See Article page e193.

\section{Commentary: Coronary artery bypass grafting in patients with coronavirus disease 2019 (COVID-19): Darkness cannot drive out darkness}

\author{
Dominique Vervoort, $\mathrm{MD},{ }^{\mathrm{a}}$ and Tom C. Nguyen, $\mathrm{MD}^{\mathrm{b}}$
}

Coronavirus disease 2019 (COVID-19) marks the start of a new era, turning the cardiovascular community upside down. In 5 months, more than 5 million cases have been confirmed globally-millions more undoubtedly undetected. COVID-19 presents with substantial pathologic manifestations, and cardiac surgery in the COVID-19 era represents unchartered territory. In the words of Martin Luther King, Jr, "Darkness cannot drive out darkness: only light can do that." With their excellent case report of coronary artery bypass grafting $(\mathrm{CABG})$ in a patient positive for COVID-19 with 3-vessel coronary disease, Salna and colleagues ${ }^{1}$ bring informative light in times of darkness and uncertainty. Despite normally being a low-risk procedure, the patient died from postoperative acute respiratory distress syndrome, probable myocarditis, and microangiopathic coagulopathy. Although the authors note that preoperative knowledge of COVID-19 would have altered their management, they recognize that "[e]mergent cardiac surgery cannot stop in the wake of a global pandemic." $\mathrm{We}$ agree and add that our Hippocratic oath to take care of patients cannot stop amidst rain, sleet, snow, or global crisis.

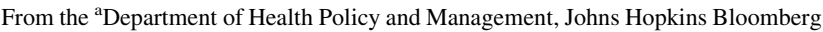
School of Public Health, Baltimore, Md; and ${ }^{\mathrm{b}}$ Department of Cardiothoracic and Vascular Surgery, University of Texas Health Science Center Houston, McGovern Medical School, Houston, Tex.

Disclosures: Dr Nguyen is a consultant for Edwards LifeSciences, Abbott, and LivaNova. Dr Vervoort reported no conflicts of interest.

The Journal policy requires editors and reviewers to disclose conflicts of interest and to decline handling or reviewing manuscripts for which they may have a conflict of interest. The editors and reviewers of this article have no conflicts of interest.

Received for publication May 27, 2020; accepted for publication May 29, 2020; available ahead of print June 4, 2020.

Address for reprints: Tom C. Nguyen, MD, Department of Cardiothoracic and Vascular Surgery, The University of Texas Health Science Center at Houston, McGovern Medical School, 6400 Fannin St, Suite 2850, Houston, TX 77030 (E-mail: tom.c.nguyen@gmail.com).

J Thorac Cardiovasc Surg 2020;160:e197-8

0022-5223/\$36.00

Copyright (C) 2020 by The American Association for Thoracic Surgery

https://doi.org/10.1016/j.jtcvs.2020.05.061

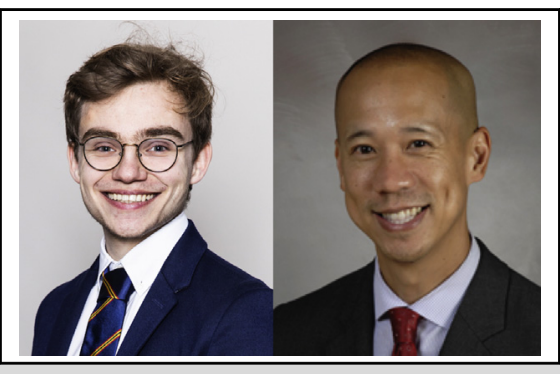

Dominique Vervoort, MD, and Tom C. Nguyen, MD

CENTRAL MESSAGE

COVID-19 complicates cardiac

surgical procedures and cardio-

vascular diseases. It is here to

stay, requiring cardiac surgeons

to adapt and prevail for the

betterment of our patients'

health.

CABGs are the most common cardiac surgical procedures, with an operative mortality of less than $2 \%$ in the United States. ${ }^{2}$ While little is known about performing CABGs in patients with COVID-19, multisystemic complications seem likely. Patients with COVID-19 present with largely unknown pathophysiologic profiles, complicating the peri- and postoperative course. Reports from Wuhan illustrated high case fatality rates among COVID-19-positive thoracic surgical patients, hinting at concerning rates among cardiac patients. ${ }^{3}$ In addition, the currently low sensitivity of reverse transcription polymerase chain reaction tests makes it difficult to adequately and timely assess preoperative COVID19 status, especially in emergent and urgent settings. ${ }^{4} \mathrm{We}$ navigate through the early, dark days of the "new normal"- a challenge to which we have to adapt.

Clinical guidelines may, therefore, need to be reconsidered during pandemics. Patients previously deemed most suited for CABGs perhaps ought to undergo percutaneous coronary interventions instead: even if suboptimal, the less-invasive nature reduces hospital length of stay and warrants less exposure for patients and providers. Where possible, preoperative screening and self-isolation provide light into patients' status. Careful preadmission and intraoperative precautions minimize risks of in-hospital infection, whereas proper risk stratification should determine the preferred intervention in light of disease severity and COVID-19. Postoperatively, strict contact isolation is necessary, and close monitoring is vital to timely respond to complications. 
The unpredictable impact of COVID-19 leads us to reexamine contemporary practices, as illustrated by the fulminant complications in the authors' case report. ${ }^{1}$ Here, $n$ equals 1 and further studies are clearly needed to unpack how practice may have to adapt for the sake of our patients. Our field has been threatened before but prevailed due to its innovative spirit and unparalleled leadership. COVID-19 is here to stay and in an ever-so-globalized world, future outbreaks are not unlikely. As Martin Luther King, Jr echoed, "Darkness cannot drive out darkness: only light can do that." In these times of darkness, we need light: only through time, sharing experiences, and application of science can we once more illuminate our patients' lives.

\section{References}

1. Salna M, Polanco A, Bapat V, George I, Argenziano M, Takeda K. A case of coronavirus disease 2019 (COVID-19) presenting after coronary artery bypass grafting. J Thorac Cardiovasc Surg. 2020;160:e193-5.

2. LaPar DJ, Filardo G, Crosby IK, Speir AM, Rich JB, Kron IL, et al. The challenge of achieving $1 \%$ operative mortality for coronary artery bypass grafting: a multiinstitution Society of Thoracic Surgeons database analysis. J Thorac Cardiovasc Surg. 2014;148:2686-96.

3. Peng S, Huang L, Zhao B, Zhou S, Braithwaite I, Zhang N, et al. Clinical course of coronavirus disease 2019 in 11 patients after thoracic surgery and challenges in diagnosis. J Thorac Cardiovasc Surg. April 10, 2020 [Epub ahead of print].

4. Fisher B, Seese L, Sultan I, Kilic A. The importance of repeat testing in detecting coronavirus disease 2019 (COVID-19) in a coronary artery bypass grafting patient. J Card Surg. May 12, 2020 [Epub ahead of print].
See Article page e193.

\section{Commentary: The era of great uncertainty}

\author{
Takashi Murashita, MD
}

The current coronavirus disease 2019 (COVID-19) pandemic has had a significant impact on the practice of cardiothoracic surgery. Owing to the increasing burden on clinical resources and concern for nosocomial spread, the number of cardiac surgery cases has decreased dramatically. One study showed a 54\% drop in cardiac surgical volume after restrictions were implemented. ${ }^{1}$ The Society of Thoracic Surgeons recently published a patient triage guidance statement for the COVID-19 pandemic. $^{2}$ All nonurgent cases are recommended to be deferred, whereas care providers need to contemplate the balance between the risk of delaying treatment and the risk of acquiring nosocomial COVID-19.

\footnotetext{
From the Division of Cardiothoracic Surgery, Department of Surgery, University of Missouri, Columbia, Mo.

Disclosures: The author reported no conflicts of interest.

The Journal policy requires editors and reviewers to disclose conflicts of interest and to decline handling or reviewing manuscripts for which they may have a conflict of interest. The editors and reviewers of this article have no conflicts of interest.

Received for publication June 5, 2020; revisions received June 5, 2020; accepted for publication June 5, 2020; available ahead of print June 27, 2020.

Address for reprints: Takashi Murashita, MD, Division of Cardiothoracic Surgery, Department of Surgery, University of Missouri, One Hospital Drive, Columbia, MO 65212 (E-mail: murashitat@health.missouri.edu).

J Thorac Cardiovasc Surg 2020;160:e198-9

$0022-5223 / \$ 36.00$

Copyright (c) 2020 by The American Association for Thoracic Surgery

https://doi.org/10.1016/j.jtcvs.2020.06.054
}

Check for updates

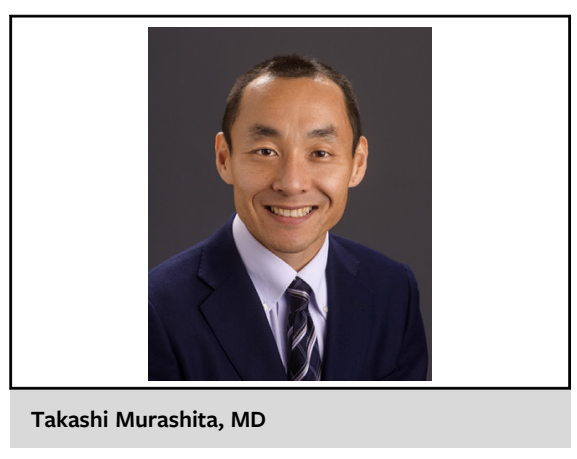

CENTRAL MESSAGE

During the COVID-19 pandemic, cardiac surgeons need to be aware that undiagnosed infection can cause unexpected catastrophic complications after urgent or emergent operations.

Because each hospital is encouraged to adopt a mechanism by which patients can be screened for COVID-19 infection perioperatively, many centers have started screening all patients undergoing elective surgery. However, in urgent or emergent situations, such as type A aortic dissection, acute coronary syndromes, and acute valvular endocarditis, patients may need to be taken to the operating room without being tested for COVID-19 infection.

In this issue of the Journal, Salna and colleagues ${ }^{3}$ report a case of a patient who underwent urgent coronary artery 